\title{
Circuitos Turísticos de Minas Gerais: uma análise a partir de ferramentas de geoprocessamento
}

\author{
Tourist Circuits in Minas Gerais: an analyses using geoprocessing tools
}

\author{
Jean Max Tavares ${ }^{1}$ \\ Jonas Antônio Vieira Junior ${ }^{2}$ \\ Simone Fernandes Queiroz ${ }^{3}$
}

\begin{abstract}
Resumo
A estratégia de regionalização proposta pelo Ministério do Turismo (2006) tem sido implementada por Minas Gerais por meio da certificação de uma série de Circuitos Turísticos (CT's) que já existiam mas sem o reconhecimento oficial pelo Estado. Como muitos municípios formadores desses circuitos são de pequeno porte e esperam na atividade turística uma redenção econômica, a sua correta estruturação é de suma importância. Assim, foram analisados os municípios pólos, as disponibilidades de acesso e os principais atrativos de seis CT's devidamente certificados utilizando pesquisa bibliográfica e ferramentas de geoprocessamento. Observou-se que existem problemas em todos os CT's no que se refere à escolha adequada do município pólo e também à semelhança entre atrativos no próprio Estado.
\end{abstract}

Palavras-chave: circuitos turísticos; Minas Gerais; regionalização.

\section{Abstract}

The strategy of regionalization proposed by the Ministry of Tourism (2006) has been implemented by the state of Minas Gerais through the certification of a series of Tourist Circuits (TC) that already existed without proper official acknowledgement. Since many of these circuit districts are rather small and hope the touristic activity will provide their economic redemption, their correct organization is highly important. Thus this purpose, we have analyzed the municipal district poles, the access conditions and the main touristic attractions of six certified tourist circuits in Minas Gerais using bibliographic research and geoprocessing tools. Problematic conditions were observed in all of the analyzed circuits, mainly in terms of the adequate choice of the municipal district pole and in relation to the similarity among State's attractions.

Keywords: tourist circuits; Minas Gerais; regionalization.

\footnotetext{
${ }^{1}$ Doutor em Economia (UFRGS); Professor de Economia (PUC/MG). E-mail: jeanpucminas@uol.com.br

${ }^{2}$ Graduando em Geografia (PUC/MG). E-mail: jonasgeografo@gmail.com.br

${ }^{3}$ Doutora em Lazer e Potencial Humano (Universidade de Deusto - Espanha); Professora de Administração e Turismo (PUC/MG). E-mail: simonequeiroz@pucminas.br
} 


\section{Introdução}

É inegável a importância que a atividade turística exerce em muitas economias. A capacidade de geração de emprego e renda, de atração de novos investimentos e de aumentar a arrecadação pública são alguns dos desdobramentos do turismo em uma região.

Dado que o homem tem se deslocado cada vez mais para outros destinos por várias razões (negócios, lazer, cultura, dentre outros), os integrantes do sistema turístico têm tentado se adaptar a essa nova realidade por meio de parcerias e uma maior proximidade com o setor público e com a comunidade.

Para muitas economias de pequeno porte - com um setor de serviços ainda incipiente e um setor secundário inexistente - a atividade turística tem sido uma "esperança" para a promoção do desenvolvimento local. Porém, para que isso ocorra, é necessária, em muitos casos, a elaboração de um produto turístico agregado de maior apelo ao turista, aumentando seu período de permanência e, consequentemente, seus gastos na região.

Essa questão é importante porque uma determinada atratividade local pode ser insuficiente para atração e, principalmente, retenção do turista. Porém, várias atratividades - localizadas em um conjunto de regiões contíguas, por exemplo - poderiam ser capazes de fazê-lo.

Esta dispersão de atratividades turísticas em vários municípios exige uma coordenação adequada de representantes locais, estimulando a cooperação, o desenvolvimento de ações em conjunto e até mesmo a competição - o que aumenta a qualidade de cada atratividade de forma individual.

Em relação ao Estado de Minas Gerais, de acordo com Oliveira e Januário (2007, p.3), “como a Constituição Federal não permite a intervenção do Estado diretamente nos municípios (...) optou-se por uma solução regionalizada, com destaque para os Circuitos Turísticos e a Estrada Real".

Criada em 2003 pelo governo de Minas Gerais, a Federação das Associações dos Circuitos Turísticos (FECITUR) possui, até o presente momento, 42 circuitos devidamente certificados e distribuídos em todas as regiões do Estado, embora existam, oficialmente, 52 Circuitos 
Turísticos (CT's) formalizados, conforme informações da Secretaria de Turismo do Estado de Minas Gerais (2009).

Como grande parte dos municípios que os compõe possui economias pouco desenvolvidas (IBGE, 2001), a criação destes circuitos é uma nova possibilidade de progresso e de geração de novas oportunidades. Portanto, sua correta estruturação é fundamental para o atendimento das expectativas de todos os envolvidos na atividade do turismo.

Porém, aparentemente, alguns desses CT's no Estado de Minas Gerais têm obtido pouco sucesso em termos de reconhecimento pelo seu público-alvo, apesar de terem sido recentemente certificados. Esta percepção é semelhante à de Domingos e Ribeiro (2008, p.3), segundo os quais "a criação dos circuitos em Minas Gerais não tem apresentado os resultados esperados, pois muitos deles se encontram em processo de formação e outros, por motivos diversos, não conseguem se consolidar como região turística".

Isto posto, este trabalho tem por finalidade discutir três aspectos relativos à estruturação de um CT, a saber, as disponibilidades de acesso, o município pólo e a características dos atrativos principais - entendendo serem estes muito importantes para o seu desenvolvimento. Dada a existência de mais de $50 \mathrm{CT}^{\prime}$ s em Minas Gerais, este artigo terá sua análise centralizada em seis deles e cujas escolhas serão justificadas na metodologia. Esta, aliás, se baseia em análises descritivas das variáveis supracitadas e também termos geográficos (criação de mapas), com o auxílio de ferramentas de geoprocessamento.

Este artigo divide-se em cinco partes, incluindo introdução e considerações finais. Após o referencial teórico, segue a apresentação da metodologia empregada. Em seguida, são apresentados os resultados obtidos. 


\section{Revisão da Literatura}

\subsection{Circuitos turísticos (CT's)}

A estruturação de CT's ainda não tem merecido a devida atenção por parte dos pesquisadores em turismo, salvo algumas exceções (Santos, 2004; Bolson, 2004; Gomes, Silva e Neto, 2006; Domingos e Ribeiro, 2008; Emmendoerfer, 2008; Gomes, Silva e Santos, 2008).

De acordo com Oliveira e Santos (2006, p.333), a organização de circuitos ou rotas turísticas se deve "à necessidade de se obter vantagens competitivas, onde a disponibilidade dos produtos e serviços turísticos deve se complementar", podendo, assim, aumentar a possibilidade de atendimento pleno às expectativas dos turistas.

Para Santos (2004), o CT deve ser formado por municípios relativamente próximos e que tenham diversos aspectos em comum e também singularidades capazes de atrair turistas.

Em princípio, uma justificativa plausível para a formação de $\mathrm{CT}^{\prime}$ s é que a infra-estrutura turística inexistente em muitos municípios de pequeno porte, principalmente em termos de hospedagem e alimentação - equipamentos turísticos fundamentais para a ampliação do tempo de estadia do turista.

Quanto a isto, Teixeira, Vicentim e Aguiar (2006) afirmam que municípios pequenos podem se aliar ao município mais desenvolvido e próximo geograficamente para, juntos, desenvolver a atividade turística. Tal atitude permitirá com que o tempo de permanência do turista seja maior como resultado dessa própria coordenação, a qual envolve equipamentos, atrativos e roteiros turísticos.

Nesse sentido, outra importante razão para a organização formal de CT's em uma dada região é que o turista pode decidir seu destino de viagem não em função apenas de um lugar específico como também pela oportunidade de estar em outros lugares próximos, usufruindo de outros atrativos turísticos, conforme afirma Santos:

Ao se decidir sobre o destino de sua próxima viagem, o turista leva em consideração todo o conjunto que compõe uma localidade e não um produto turístico isoladamente, para que tenha sua satisfação, seu "desejo" realizado. Daí a importância de se formar a imagem do local como um destino, como uma "marca" 
que irá representar não apenas produtos e serviços, mas, principalmente, a experiência que pode ser vivida ali. (Santos, 2004, p.26)

Em muitos casos, um ou dois atrativos turísticos apenas são insuficientes para atrair turistas a uma determinada região ou município ou, se o fazem, não possuem capacidade de retê-los por mais que um ou dois dias, o que pode atenuar os efeitos multiplicadores da atividade turística. Isso é importante na medida em que o deslocamento dos turistas tem ocorrido a custos crescentes, com aparente redução do tempo de estadia, inclusive.

Portanto, a criação de CT's vem auxiliar no tratamento dessa questão, com a oferta de um conjunto de atrativos não mais dispersos mas agrupados e que poderão ser visitados em um curto espaço de tempo, a partir de um município de referência (município pólo) do CT.

No Brasil, em princípio, existem poucas iniciativas quanto à organização formal de municípios para a promoção do desenvolvimento turístico regional. Em princípio, os roteiros vão sendo formados pelos próprios "desbravadores" do local e a comunidade vai se adaptando a esse fluxo criado informalmente. Com o passar do tempo, tais "lugares a serem visitados" vão se tornando “obrigatórios” para quem passa pela região.

Baseada em similaridades entre os municípios, as quais podem ser vistas de diferentes formas (gastronômicas, sociais, atrações turísticas, dentre outras), um CT pode ter as condições iniciais necessárias - mas não suficientes - para ser estruturado. Em relação ao processo de elaboração de um CT, Teixeira, Vicentim e Aguiar (2006) afirmam que diversos fatores locais tais como a atividade econômica, as características sócio-culturais e as similaridades entre os municípios são formadores de uma identidade regional que acaba resultando na principal atração ou chamariz do CT e cujo nome deve induzir o turista a fazer a associação com esses fatores locais supracitados.

Mas é claro que a participação do setor público - em conjunto com o setor privado - tem papel importante e, na verdade, imprescindível para a formação e o desenvolvimento dos CT's, que vai desde a formatação de sua estrutura, com regras e diretrizes a serem seguidas pelos municípios integrantes, até ao treinamento de seus gestores e demais participantes. Sobre o papel do poder público no processo de criação de um CT, Dreher e Salini (2008) descrevem a dinâmica do mesmo e afirmam que: 
(...) os municípios necessitam compreender claramente esta proposta e, principalmente, seu papel enquanto agentes deste processo, enquanto o governo como motivador da regionalização cria as políticas públicas e define regiões turísticas de posse de dados e (in)tenções dos agentes regionais. Neste ínterim, os territórios são fragmentados em novas realidades espaciais e políticas, ou seja, em regiões turísticas definidas. Após esta definição, parte-se para a elaboração de políticas públicas específicas, que possam resultar na ordenação das ações de um desenvolvimento turístico regionalizado. Em decorrência disto, criam-se produtos turísticos regionais. (Dreher; Salini, 2008, p.1)

Segundo Cravo (2004), criar um CT envolve não apenas fazer um inventário turístico dos locais que poderão compô-lo como também verificar quais distâncias devem ser percorridas, o tempo que se leva e quais as condições de pavimentação existentes. Portanto, tal afirmação reitera a importância das condições de acesso do CT, bem como a escolha do município pólo, o qual deve considerar vários aspectos e não apenas sua infra-estrutura turística.

De forma geral (assim como em Minas Gerais), cada CT é formado por um município-pólo ou por "base distribuidora" de turistas para os demais municípios, devido à existência de uma oferta mais ampla de equipamentos turísticos e por unidades turísticas, que são, naturalmente, os municípios remanescentes, com fraco poder de retenção de turistas, devido não só à insuficiente infra-estrutura como também a um número pequeno de atrativos - embora significativos - que justifiquem uma estadia por mais tempo.

Portanto, o centro turístico e as unidades turísticas podem assumir uma ajuda mútua, visto que estas últimas também assumem o papel de fornecedoras de insumos para o primeiro e obtém receitas dos turistas com sua gastronomia e artesanato, principalmente (Bolson, 2006).

Porém, da sua estruturação, certificação e até o seu reconhecimento enquanto destino turístico, muitas dificuldades poderão ser enfrentadas, embora certamente superáveis. Nesse sentido, uma questão relevante para o sucesso de um CT consiste na escolha correta do seu município pólo, visto que este terá que prestar o suporte necessário em termos de infraestrutura para o "acolhimento e distribuição" dos turistas do CT, além de possuir também atrativos turísticos relevantes.

Outro aspecto relevante em relação ao município pólo é que este deve estar geograficamente situado em um ponto estratégico do $\mathrm{CT}$, ou seja, localizado próximo e, se possível, 
equidistante de todas as unidades turísticas, de forma a ser possível o deslocamento e o retorno em menos de 24 horas, o que está diretamente relacionado às condições de acesso ao CT. Caso contrário, poderá ocorrer a "captura" dos seus turistas pelo município pólo de um CT contíguo, seja por questões de acesso, infra-estrutura ou por possuir mais atrativos turísticos. Além disso, a ocorrência de não contigüidade entre os municípios (ou seja, municípios) de um mesmo CT também pode enfraquecer o seu desenvolvimento e também serem "capturados" por outro município pólo.

Outra questão importante para o desenvolvimento de um CT refere-se às disponibilidades de acesso no CT, já que a grande maioria dos municípios brasileiros é alcançada via ônibus (de linha ou fretado) ou por automóvel quando se trata de turismo (FIPE, 2006).

Isso significa que se a acessibilidade for insatisfatória, o fluxo de turistas no circuito poderá ficar restrito apenas ao município pólo. Tal importância é confirmada por Santos (2004, p.29), segundo o qual "para que ocorra a (...) integração regional entre os municípios de um mesmo circuito, vias de acesso compatíveis são fundamentais à complementaridade entre os atrativos, os meios de transporte, os equipamentos e os serviços e para o fortalecimento da cadeia produtiva do setor (...)".

Por fim, a verificação da tipologia dos atrativos principais do CT também é igualmente importante nesse processo, já que $\mathrm{CT}^{\prime}$ s contíguos poderão competir entre si antes mesmo de se desenvolverem individualmente. Como já mencionado, a competição e a cooperação entre os destinos turísticos são importantes, mas, pelo menos em uma etapa inicial, as condições de atração dos turistas devem ser equivalentes, sob pena de haver uma "atrofia" de determinado CT. Mesmo assim, a questão é problemática, visto que um CT pode "ganhar a preferência" dos turistas em detrimento de outro por razões que fogem a dos atrativos turísticos em si mas por melhores condições de infra-estrutura e de acesso, por exemplo.

\subsection{Circuitos turísticos de Minas Gerais}

Segundo o Decreto Lei 43.231, de junho de 2003, que institucionaliza os CT's em Minas Gerais, um CT é "é um conjunto de municípios de uma mesma região, com afinidades culturais, sócias e econômicas que se unem para organizar e desenvolver a atividade turística regional (...) através da integração contínua dos municípios (...)”. 
De acordo com a Secretaria de Turismo do Estado de Minas Gerais (2009), uma das funções da entidade civil responsável pela gestão dos CT's é o de "identificar os municípios que tenham uma afinidade turística ou que se complementam turisticamente, que estejam num raio aproximado de 100 km". Em seguida, deve-se "definir através da identidade comum regional dos municípios participantes o nome do Circuito Turístico".

Segundo Emmendoerfer (2008, p.2), "esta estratégia foi idealizada como meio para se estruturar a atividade turística municipal e regional, buscando atrair mais turistas a determinada região, bem como estimular sua permanência ali por um tempo maior (...)".

Para se obter o certificado de reconhecimento expedido pelo Governo de Minas Gerais, "os Circuitos Turísticos deverão contar com pelo menos um ano de existência formal e serem constituídos por no mínimo cinco municípios de uma mesma região que tenham afinidades turísticas", conforme texto da lei 43.231 supracitada, além do cumprimento de outras diretrizes, tais como o levantamento das ofertas turísticas existentes e a manutenção de um posto de informações turísticas localizados estrategicamente no circuito.

A quantidade de municípios pertencentes a um CT em Minas Gerais varia de cinco - tais como os CT's Caminhos de Indaiá, Caminhos do Cerrado e Malhas do Sul de Minas - a 20, como é o caso do CT Pico da Bandeira. Quanto ao número de municípios apropriado a um CT, Gomes, Silva e Neto (2006, p.327) afirmam que "circuitos muito grandes com, por exemplo, 28 municípios, não têm conseguido avançar no seu processo de organização".

Os nomes dos $\mathrm{CT}^{\prime}$ 's trazem consigo elementos que certamente fazem parte não só da realidade dos lugares mas também do imaginário acerca do que é o produto turístico Minas Gerais como um todo, a saber, serras (Serras de Minas, Serra do Brigadeiro, Serras e Cachoeiras, Serras Verdes do Sul de Minas), caminhos (Caminhos Gerais, Caminhos do Sul de Minas, Caminho Novo, dentre outros), riqueza mineral e arqueológica (Diamantes, Grutas, do Ouro), além de referências ao café (Montanhas cafeeiras de Minas) e seus imensos recursos hídricos (Lago Três Marias, das Águas, dos Lagos, dentre outros).

Em Minas Gerais, apesar do mesmo possui a maior malha rodoviária do Brasil, nem todos os municípios possuem boa acessibilidade, principalmente no que se refere à qualidade das vias. Além disso, as condições de acesso parecem ter relação inequívoca com a distância dos 
grandes centros, ou seja, quanto mais distante for um CT de um grande centro, piores serão suas disponibilidades de acesso, o que se traduz na quantidade ofertada de vias, na qualidade das mesmas e principalmente em sua sinalização turística. Tal percepção talvez possa ser confirmada através da análise das condições de acesso de CT's localizados mais distantes da capital mineira ou que fazem divisa com os Estados de São Paulo e Rio de Janeiro, por exemplo.

Por exemplo, um circuito localizado próximo ao conhecido CT das Águas, no sul de Minas Gerais, deve concentrar seus esforços de divulgação em um atrativo distinto, pelo menos inicialmente, dado que a competição seria praticamente inviável. Essa preocupação é aparentemente legítima, pois em trabalho recente sobre o CT Grutas e Mar de Minas, Domingos e Ribeiro (2008, p.3) fazem a seguinte indagação: "se alguns circuitos estão consolidados e outros não, quais são os entraves e quais são os fatores que podem dinamizar a implantação desse modelo de gestão?".

Em pesquisa realizada por Gomes, Silva e Santos (2008, p.14) junto aos gestores de CT's de Minas Gerais, os autores verificaram que "a falta de infra-estrutura básica, a falta de conhecimento sobre turismo por parte da população local e a escassez de mão de obra qualificada são fatores que dificultam a consolidação do CT", dentre outros.

Esses resultados remetem à importância das disponibilidades de acesso de um CT (pois deve fazer parte da mencionada falta de infra-estrutura básica), à escolha adequada do município pólo (deve ser um município que possua uma população que "sinta a importância do turismo" e conheça seus atrativos turísticos, além de oferecer uma mão de obra qualificada e vários equipamentos turísticos) e, é claro, da tipologia das atratividades turísticas existentes.

\section{Metodologia}

Em relação aos objetivos, a pesquisa é do tipo exploratória (pretende discutir um problema relativamente pouco investigado) e descritiva (devida à caracterização de alguns CT's enquanto disponibilidades de acesso, município pólo e seus atrativos principais). Quanto ao procedimento de coleta dos dados, esta pesquisa é do tipo estudo de caso, já que as inferências 
obtidas a partir da análise dos $\mathrm{CT}^{\prime}$ s escolhidos devem ser estendidas, de uma maneira geral, aos demais.

Em virtude do grande número de CT's em Minas Gerais, foram considerados para análise seis CT's devidamente certificados, a saber: a) Serra Geral do Norte de Minas e Lago de Irapé, ambos pertencentes à região turística conhecida como Terras do Velho Chico e escolhidos em função de sua importância enquanto propulsores do desenvolvimento sócio-econômico ainda tão incipiente nessa parte do Estado; b) Grutas e Mar de Minas e Circuito Verde - Trilha dos Bandeirantes, o primeiro situado na região turística Caminhos do Interior (centro-oeste) e o segundo na região turística Caminho das Gerais (centro do Estado) e foram selecionados em função de um estudo recente feito por Domingos e Oliveira (2008) que apontam alguns entraves para o desenvolvimento do CT Grutas e Mar de Minas; c) Nascentes das Gerais e Terras Altas da Mantiqueira, ambos no sul do Estado, situados na região turística conhecida como Estâncias do Sul e foram escolhidos em virtude de estarem próximos ao CT das Águas - um conceituado destino turístico de Minas Gerais. Os seis circuitos escolhidos totalizam 58 municípios, conforme Quadro 1.

Os CT's escolhidos foram analisados em termos de município pólo, condições de acesso e da tipologia dos atrativos principais por meio de informações disponibilizadas pela Secretaria de Turismo do Estado de Minas Gerais, Federação dos Circuitos Turísticos de Minas Gerais (FECITUR-MG) e pelos próprios CT's do Estado. Além disso, foram gerados mapas a partir da base cartográfica digital do IBGE (2005), os quais servirão de auxílio para a análise das variáveis objetos de estudo. Tais mapas foram elaborados com o auxílio do SIG - Sistemas de Informação Geográficos - ArcGIS 9.2. 
Quadro 1 - Circuitos turísticos analisados em Minas Gerais

\begin{tabular}{|c|c|c|l|}
\hline $\begin{array}{c}\text { Circuitos } \\
\text { Turísticos }\end{array}$ & $\begin{array}{c}\text { Município } \\
\text { pólo }\end{array}$ & $\begin{array}{c}\text { Quantidade } \\
\text { de municípios }\end{array}$ & \multicolumn{1}{|c|}{ Nome dos municípios } \\
\hline $\begin{array}{c}\text { Serra Geral do } \\
\text { Norte de Minas }\end{array}$ & Mato Verde & 17 & $\begin{array}{l}\text { Catuti, Espinosa, Gameleiras, Jaíba, Janaúba, } \\
\text { Mamonas, Mato Verde, Monte Azul, } \\
\text { Montezuma, Nova Porteirinha, Pai Pedro, } \\
\text { Porteirinha, Riacho dos Machados, Rio Pardo de } \\
\text { Minas, Santo Antônio do Retiro, Serranópolis de } \\
\text { Minas, Verdelândia. }\end{array}$ \\
\hline $\begin{array}{c}\text { Lago de Irapé } \\
\text { Grutas e Mar de } \\
\text { Minas }\end{array}$ & Frão Mogol & 5 & $\begin{array}{l}\text { Berilo, Botumirim, Chapada do Norte, Cristália, } \\
\text { Grão Mogol. }\end{array}$ \\
\hline $\begin{array}{c}\text { Verde - Trilha } \\
\text { dos } \\
\text { Bandeirantes }\end{array}$ & Betim & 9 & $\begin{array}{l}\text { Boa Esperança, Campo Belo, Candeias, Córrego } \\
\text { Fundo, Formiga, Iguatama, Pains, Pimenta, } \\
\text { Lagoa da Prata. }\end{array}$ \\
\hline $\begin{array}{c}\text { Terras Altas da } \\
\text { Mantiqueira }\end{array}$ & Passa Quatro & 8 & $\begin{array}{l}\text { Betim, Conceição do Pará, Esmeraldas, Florestal, } \\
\text { Juatuba, Pitangui, Itaúna, Ribeirão das Neves, } \\
\text { São Gonçalo do Pará. }\end{array}$ \\
\hline $\begin{array}{c}\text { Nascentes das } \\
\text { Gerais }\end{array}$ & Passos & 10 & $\begin{array}{l}\text { Alagoa, Delfim Moreira, Itamonte, Itanhandu, } \\
\text { Marmelópolis, Passa Quatro, Pouso Alto, São } \\
\text { Sebastião do Rio Verde. }\end{array}$ \\
\hline
\end{tabular}

Fonte: Elaborada pelos autores a partir de dados da Secretaria de Turismo do Estado de Minas Gerais (2009).

\section{Resultados}

\subsection{CT Serra Geral do Norte de Minas}

a) Município pólo - Refere-se a Mato Verde, o qual possui pouco mais de 13 mil habitantes (IBGE, 2001), um IDH-M muito baixo (0,669, de acordo com o PNUD, 2003) e dista $630 \mathrm{Km}$ de Belo Horizonte. Em 2000, mais de 1/3 da população com mais de 25 anos era considerada analfabeta, segundo dados do Ministério da Educação (2001) e com apenas três meios de hospedagem, segundo informações da prefeitura do município (MATO VERDE, 2009). Portanto, em termos de mão-de-obra qualificada, é preciso que haja mais investimentos em educação formal e treinamento específico para o turismo, bem como estímulos à instalação de novos meios de hospedagem ou ampliação daqueles já existentes para que o município pólo possa cumprir uma de suas principais funções, que é a de "receber e distribuir" os turistas. 
Observando-se apenas pela posição geográfica, Mato Verde seria a melhor indicação para município pólo do $\mathrm{CT}$, pois se localiza no centro da região, embora algumas unidades turísticas possam ser "assediadas” pelo município pólo do CT Lago de Irapé (Mapa 1), conforme será visto na discussão a seguir.

b) Disponibilidades de acesso - O CT Serra Geral ao Norte de Minas é de grande abrangência (17 municípios) e baixa densidade de rodovias em sua malha, visto que apenas a BR-122 percorre seu território de norte a sul, passando pelo seu município pólo Mato Verde, como também a MG-401 realiza o mesmo trajeto na porção oeste (Mapa 2). Como o CT possui muitos municípios, torna-se mais difícil deslocar até à unidade turística e retornar ao município pólo em apenas um dia, usando transporte que não o aéreo. E ainda, unidades turísticas como Nova Porteirinha, Riacho dos Machados e Serranópolis de Minas poderão ser “capturados” pelo município pólo do CT Lago de Irapé - Grão Mogol, considerando apenas as condições de acesso, já que é próximo a esses municípios (Mapa 1). Enfim, a dependência do CT Serra Geral ao Norte de Minas em relação às condições de acesso é enorme, o que exigirá o investimento do poder público, tanto na criação quanto na manutenção das vias.

c) Tipo principal de atrativo turístico - O CT possui atrativos que estão associados principalmente ao turismo de aventura, dada a existência de grande diversidade de recursos naturais na região, como, por exemplo, serras, cachoeiras, grutas, águas termais, rapel e escalada. Portanto, quanto à tipologia dos atrativos turísticos, o CT Serra Geral do Norte de Minas compete diretamente com um grande número de outros circuitos (CT Grutas e Mar de Minas, CT Trilha Verde dos Bandeirantes, CT Terras Altas da Mantiqueira, dentre outros) presentes em Minas Gerais, o que exigirá por parte dos gestores de cada município e do próprio $\mathrm{CT}$ a criação e a divulgação de seus diferenciais enquanto destino turístico, não apenas pela similaridade dos atrativos turísticos, mas também pela distância dos principais centros emissores de turistas da região Sudeste (Belo Horizonte, Rio de Janeiro e São Paulo não necessariamente nessa ordem), segundo a FIPE (2006).

\subsection{CT Lago do Irapé}

a) Município pólo - A escolha pelo município de Grão Mogol tem algumas ressalvas. Com população inferior a 15 mil habitantes (IBGE, 2001), situa-se a mais de $550 \mathrm{Km}$ da capital de 
Estado, possui um IDH-M muito baixo (0,653), segundo o PNUD (2003) e pouquíssimas opções de hospedagem (GRÃO MOGOL, 2009). Portanto, em termos de infra-estrutura, o município necessitaria, em princípio, de mais investimentos em equipamentos turísticos que possam permitir com que cumpra sua função de pólo "acolhedor e distribuidor" de turistas (Mapa 1).

b) Disponibilidades de acesso - A MG-307 e a BR-251 se tocam no município de Grão Mogol. Percebe-se que a malha rodoviária não é adensada: por exemplo, o turista terá dificuldades para se deslocar de Grão Mogol para os municípios de Berilo e Chapada do Norte - ambos integrantes do CT (Mapa 2). Porém, todos os municípios pertencentes ao CT possuem alguma rodovia como acesso, o que pode facilitar seu gerenciamento. 


\section{Mapa 1 - Circuitos turisticos analisados e seus municipios pólos,} Minas Gerais - 2009

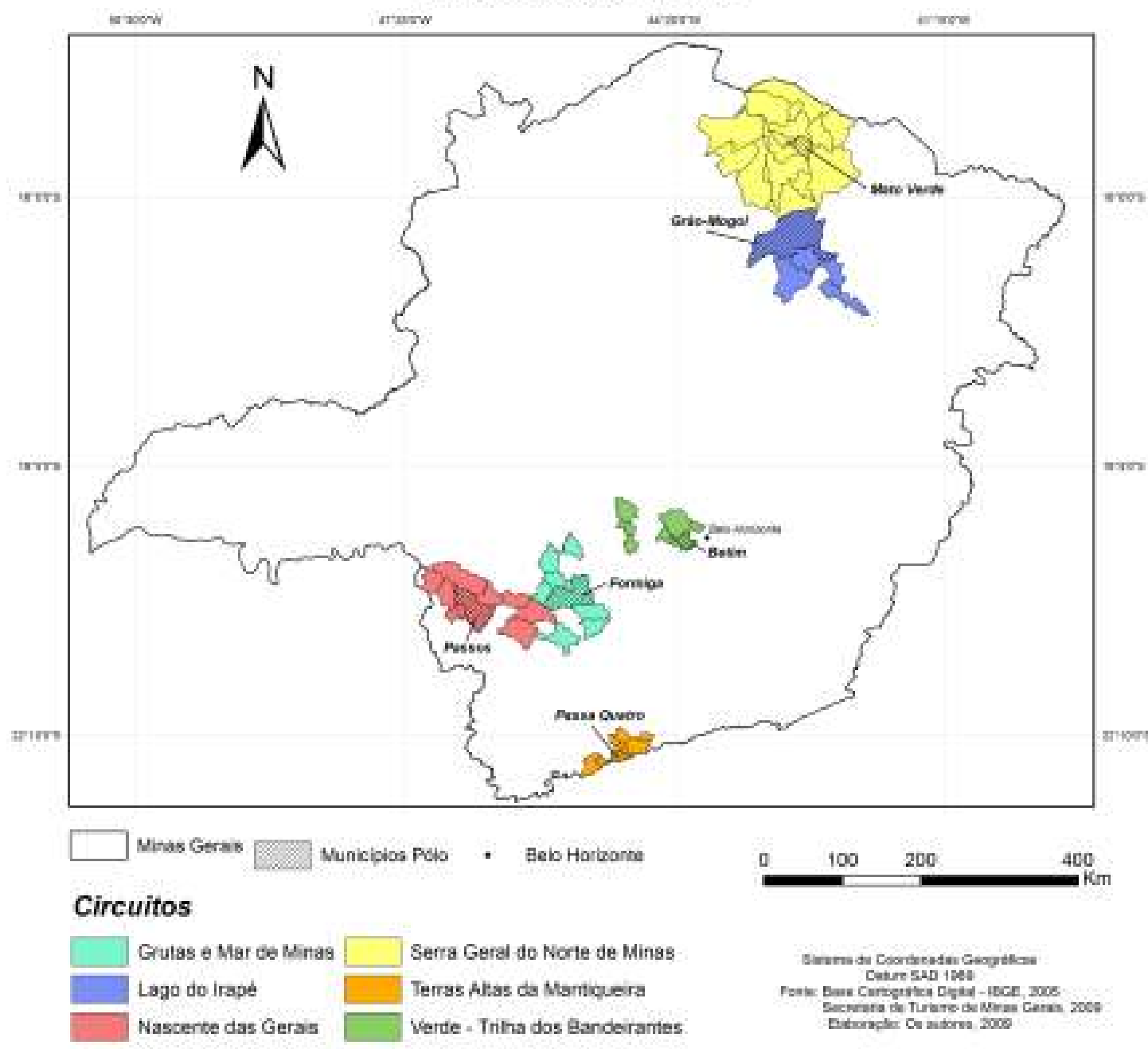

c) Caracterização dos atrativos turísticos - O destaque principal do CT - e que leva o seu nome - é mesmo o Lago de Irapé, que, localizado no município de Cristália, é fruto do represamento de água na região para geração de energia elétrica, onde se pratica diversos esportes náuticos. Pela região também são encontradas trilhas (município de Botumirim) e praias de rios (formadas pelo Rio Araçuaí, no município de Berilo). Porém, são atrativos muito similares a outros no Estado de Minas Gerais (CT Grutas e Mar de Minas) com o agravante que Grão Mogol apresenta - segundo informações da SETUR-MG (2009), apenas dois atrativos - a Igreja Matriz de Santo Antônio e o Parque Estadual de Grão Mogol (com 
trilhas e cachoeiras) - que também possui uma concorrência muito grande com outros $\mathrm{CT}^{\prime}$ 's de Minas Gerais. Dessa forma, o CT Lago de Irapé teria que investir na diferenciação de seus atrativos turísticos, destacando elementos de singularidade em relação aos demais do Estado, a fim de consolidar a região em termos de destino turístico.

\subsection{CT Grutas e Mar de Minas}

a) Município pólo - O CT é composto por nove municípios e tem em Formiga o município de referência em termos sócio-econômicos. O aspecto positivo desse CT é que Formiga está bastante centralizada geograficamente (Mapa 1), o que pode facilitar a "a distribuição dos turistas" para as unidades turísticas do CT. Além disso, Formiga possui mais de 60 mil habitantes (IBGE, 2001) e, segundo informações da prefeitura, tem nove pousadas/hotéis para hospedar os turistas do CT, bem como 33 estabelecimentos de saúde, o que pode contribuir para o fortalecimento do município enquanto referência na região (FORMIGA, 2009). Porém, o CT possui dois municípios disjuntos (Lagoa da Prata e Boa Esperança), ou seja, não contíguos aos demais, visto que isso pode implicar na "captura" desses por um município pólo de um CT vizinho, além de implicar em maiores tempos de deslocamento. Por exemplo, Lagoa da Prata (distante $70 \mathrm{Km}$ de Formiga), um importante município desse CT, poderia ser "capturada" por Bom Despacho, que fica a apenas $45 \mathrm{Km}$, possui quase 40 mil habitantes (IBGE, 2001) mas que não pertence a esse CT.

b) Disponibilidades de acesso - O CT Grutas e Mar de Minas está situado a leste do circuito Nascente das Gerais, e, por sua vez, está mais próximo à Belo Horizonte. Isso contribui para a densidade relativamente alta da sua rede rodoviária. Formiga, município pólo, é uma região nodal onde é notável o entroncamento das rodovias BR-354, MG-050 e MG-439, além da MG-164 e BR-369 ao sul do circuito (Mapa 2), o que permite boas condições de acessibilidade aos turistas, ligando o município pólo às unidades turísticas do CT.

c) Tipo principal de atrativo turístico - O CT possui, evidentemente, atrativos que remetem ao seu nome, ou seja, grutas, sítios arqueológicos (como os municípios de Arcos e Pains), cachoeiras, lagoa (município de Lagoa da Prata, em destaque) e lagos, sendo o principal deles o de Furnas, onde é possível fazer esportes náuticos e pesca esportiva. Como o município de Córrego Fundo (o mais recente a integrar-se no CT) se destaca pela produção de cachaças e 
de peças artesanais, o CT tem boa diversidade de atrativos para os turistas, abrangendo diversos tipos de turismo. Mesmo assim, o CT Grutas e Mar de Minas compete com outros CT's no Estado e outros destinos turísticos situados no litoral (como, por exemplo, as praias do Espírito Santo e do sul da Bahia). Seria necessário verificar também a presença do turismo residencial em Furnas - turistas que adquiriram ou construíram imóvel na região do Lago de Furnas - o que certamente diminui o efeito multiplicador do turismo pelo uso menos freqüente de restaurantes e de meios de hospedagem (pousadas e hotéis).

\subsection{CT Verde - Trilha dos Bandeirantes}

a) Município pólo - O CT é composto por nove municípios e tem em Betim seu município pólo 9 (Mapa 1). Porém, como está localizado na região metropolitana de Belo Horizonte, a capital poderia capturar os turistas do CT tanto em termos de hospedagem quanto de gastronomia e "substituir" o município pólo do CT Verde - Trilha dos Bandeirantes nesses aspectos, já que sua distância é inferior a $30 \mathrm{Km}$. Além disso, Betim não possui, aparentemente, nenhum "apelo turístico", sendo conhecida, aliás, como um dos municípios de maiores PIB's do Brasil (IBGE, 2001) e por situar uma grande empresa automobilística e seus fornecedores, o que lhe dá um caráter essencialmente industrial. Outro agravante desse CT é que alguns de seus municípios (Itaúna, principalmente) estão mais próximos a Divinópolis importante cidade da região, com mais de 200 mil habitantes (IBGE, 2001) - que de Betim. Por fim, os municípios de Pitangui, São Gonçalo do Pará e Conceição do Pará não são contíguos a nenhum dos demais municípios do CT, o que pode dificultar sua consolidação enquanto região turística. Portanto, em princípio, Betim não seria a melhor escolha em termos de município pólo do CT Verde - Trilha dos Bandeirantes. 
Mapa 2 - Disponibilidade de acesso dos CT's analisados em Minas Gerais, 2009
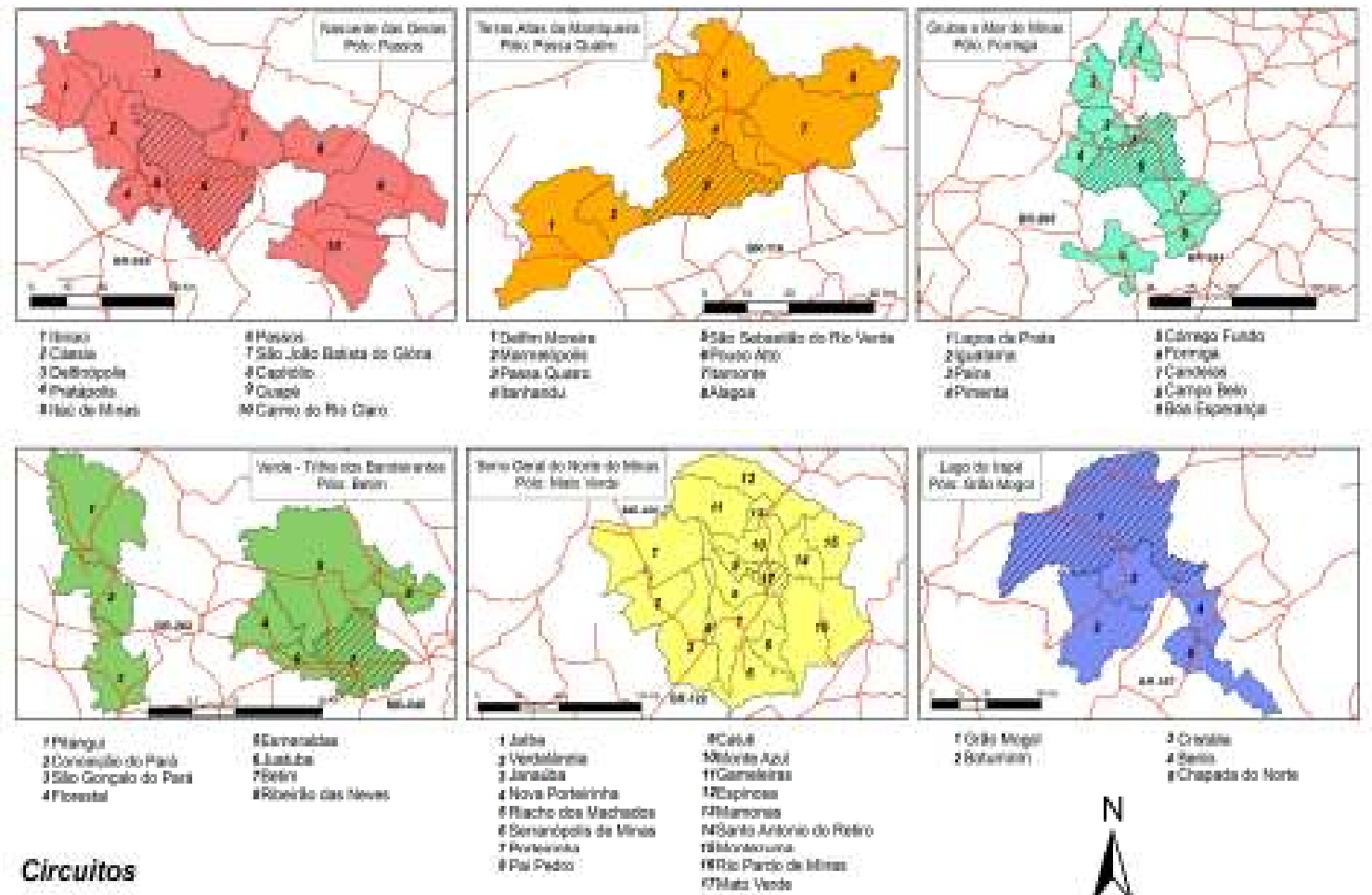

\section{Circuitos}

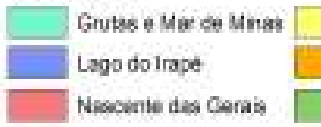

Serrs Gera co Norle de Mrnis

Terras Ayas ds Mambquera Warde - TeFa chos Bandecrafts:

Rodovias

Muniópios Pola

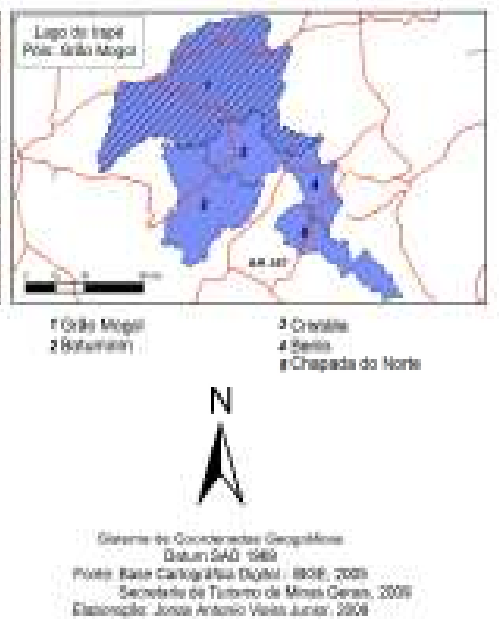

b) Disponibilidades de acesso - o CT Verde - Trilha dos Bandeirantes possui boas disponibilidades de acesso considerando o número de rodovias que interceptam seu território (Mapa 2). Essa alta densidade de vias é produto de sua localização - próxima a capital mineira e interceptada por uma série de rodovias (MG-430, MG-423, MG-060, BR-262 e próximo a MG-040), conforme se observa no Mapa 2. Cabe ressaltar o fato de que a simples existência de eixos viários não determina a qualidade do acesso pelos turistas. Atributos como pavimentação, implementação e estado da via devem ser considerados para melhor precisão no processo de avaliação dessas condições.

c) Caracterização dos atrativos turísticos - O CT tem um forte vínculo com o turismo religioso, além do turismo de aventura e, em menor grau, com o turismo de negócios (este último em virtude do município pólo Betim). Porém, teria que se verificar qual o impacto da sazonalidade exercida principalmente sobre o turismo religioso (em função da periodicidade 
das festas realizadas), embora certamente esse efeito seja reduzido em destinos muito consagrados, tal como Aparecida do Norte, em São Paulo. O turismo de aventura - com rios, cachoeiras e trilhas - tem uma competição intensa com outros CT's, inclusive com os analisados neste trabalho. Portanto, o CT Verde Trilha dos Bandeirantes precisaria investir em equipamentos turísticos de qualidade (principalmente para competir com Belo Horizonte) e formatar roteiros que maximizem o tempo de lazer do turista, aproveitando, claro, da farta malha rodoviária presente no $\mathrm{CT}$.

\subsection{CT Terras Altas da Mantiqueira}

a) Município pólo - O CT é formado por nove municípios, sendo Passa Quatro sua principal referência, embora possua menos de 15 mil habitantes (IBGE, 2001) e uma incipiente rede hoteleira. Como o município está situado na microrregião de São Lourenço, o qual tem larga tradição na atividade turística e rede hoteleira mais desenvolvida, o "poder de atração e de distribuição" de turistas por Passa Quatro poderia ficar abaixo de seu potencial (Mapa 1). Em termos de proximidade, para o turista conhecer os atrativos de São Sebastião do Rio Verde, Alagoa e Pouso Alto - municípios formadores do CT - talvez seja mais conveniente hospedar-se em São Lourenço. Outra possível consideração a ser feita é se o município de Itamonte poderia assumir o papel de município pólo, já que possui 19 meios de hospedagem (entre hotéis, pousadas, chalés e campings) e está a menos de $300 \mathrm{Km}$ de São Paulo e a 230 Km do Rio de Janeiro, segundo informações da prefeitura do município (ITAMONTE, 2009). O aspecto positivo é que Passa Quatro, em termos de CT Terras Altas da Mantiqueira, está bem localizado - praticamente no centro da região, conforme Mapa 1, além do fato de que não há nenhum município que não seja contíguo com os demais.

b) Disponibilidades de acesso - o CT Terras Altas da Mantiqueira apresenta apenas a MG158, saindo de São Paulo como SP-052, como rodovia principal em seu pólo (Passa Quatro). A malha rodoviária nesse circuito não é adensada, talvez em razão do seu relevo. A situação é mais crítica nos municípios de Marmelópolis e Alagoa, em que não se verifica nenhuma rodovia, o que pode dificultar o acesso dos turistas (Mapa 2).

c) Características dos atrativos turísticos - Predomina entre os atrativos turísticos do CT aqueles ligados ao turismo rural, ao eco-turismo e ao turismo de serra. Por meio de rios, 
cachoeiras, corredeiras e trilhas, é possível praticar quase todo tipo de esporte radical, além de passeio de trem que sai de Passa Quatro e vai até as proximidades com a divisa do Estado de São Paulo. Destaca-se, mas em menor grau, o potencial para turismo gastronômico, principalmente em razão da baixa temperatura da região, possibilitando o consumo de vários produtos que são associados a este clima. Observa-se, mais uma vez, que os atrativos turísticos do CT Terras Altas da Mantiqueira competem com vários outros CT's, até porque esses atrativos realmente predominam em todo Estado de Minas Gerais.

\subsection{CT Nascente das Gerais}

a) Município pólo - Em princípio, de todos os municípios pólos verificados neste estudo, Passos talvez se constitua na escolha mais acertada, amparada por diversas razões (Mapa 1). Com uma população de quase 100 mil habitantes (IBGE, 2001), se situa em posição estratégica dentro do próprio CT - relativamente eqüidistante de todos os demais municípios. Possui, de acordo com a prefeitura, 19 hotéis, dois hotéis fazenda e mais de 100 fábricas ligadas à confecção, (PASSOS, 2009). Portanto, aparentemente, não existiria um município em melhores condições de se tornar pólo de referência para o CT. As únicas ressalvas a serem feitas referem-se à pequena quantidade de atrativos turísticos desse município e a distância considerável até o município de Guapé, um dos integrantes do CT.

b) Disponibilidades de acesso - o CT Nascente das Gerais possui em seu pólo o cruzamento entre a BR-146 e a MG-050, o que pode facilitar, num primeiro momento, seu acesso. Percebe-se que a MG-334 faz um corte diagonal na borda oeste do CT, e o contrário ocorre na porção leste devido à menor variedade de eixos viários, indicando que o CT dispõe de boas condições de acesso, principalmente no eixo município pólo - unidades turísticas (Mapa 2).

c) Características dos atrativos turísticos - O CT tem no Lago de Furnas seu principal atrativo, permitindo lazer e a prática de esportes náuticos e de pesca esportiva, por exemplo. Em segundo plano estão as grutas, as cachoeiras e as montanhas. Convém destacar o turismo religioso existente em Cássia, município do CT. Verifica-se, portanto, que este CT tem boas condições de competir com os demais CT's e que seu desenvolvimento dependerá de uma divulgação eficiente e da participação de toda a comunidade envolvida. 


\section{Considerações finais}

Como a demanda turística tem crescido mundialmente, muitas regiões passaram a enxergar o turismo como um dos motores para o crescimento de suas economias.

Consequentemente, aumentou a competição entre os destinos turísticos, exigindo dos mesmos organização e profissionalismo na gestão desta atividade, além de uma estreita parceria com o poder público.

Nesse sentido, o governo mineiro tem promovido algumas ações e, dentre elas, a certificação de CT's já organizados formalmente por pelo menos há um ano, o que lhes garante acompanhamento da Secretaria de Turismo do Estado de Minas Gerais em termos de treinamento e recursos.

Para o sucesso desses $\mathrm{CT}^{\prime}$ s diversas variáveis devem ser levadas em consideração. Dentre elas, estão as disponibilidades de acesso, a escolha pelo município pólo e a tipificação dos atrativos turísticos. Como existem poucas metodologias específicas que orientem a formação e a estruturação de circuitos, este trabalho fez uma análise descritiva e geográfica (usando ferramentas de geoprocessamento) de seis dos 42 circuitos já certificados em Minas Gerais.

Verificou-se que a escolha pelos municípios pólos destes circuitos apresenta vários problemas, tanto em termos de infra-estrutura suficiente para "receber e distribuir" os turistas para os demais municípios quanto em termos de localização, visto que os turistas poderiam ser "capturados" por municípios importantes e adjacentes. Em relação às condições de acesso, os $\mathrm{CT}^{\prime}$ 's analisados possuem, em geral, boa disponibilidade de vias. Esta, porém, diminui à medida que os municípios se afastam em direção ao norte de Minas e aumentam ao se aproximarem da capital ou dos Estados do Rio de Janeiro e São Paulo. Por fim, no que se refere aos atrativos turísticos, percebe-se que muitos $\mathrm{CT}^{\prime} \mathrm{s}$ devem competir de forma intraestadual em Minas Gerais dada a semelhança entre seus atrativos, o que pode significar, por um lado, maior busca pelo aprimoramento dos serviços oferecidos.

Conclui-se, em princípio, que os $\mathrm{CT}^{\prime}$ s devem levar em conta vários aspectos antes de sua organização formal, pois, se analisados criteriosamente, poderão contribui positivamente para o desenvolvimento local e regional, além de otimizar recursos públicos e privados. Nesse 
sentido, deve-se ter uma atenção especial à escolha do município pólo, pois é a partir dele que os turistas visitarão as unidades turísticas do CT.

Recomenda-se, enfim, não apenas a extensão da análise para os demais CT's certificados em Minas Gerais como também a inclusão de outras variáveis igualmente importantes, como, por exemplo, a qualidade dos atrativos turísticos, a preservação ambiental e as possibilidades de entretenimento.

\section{Referências}

BOLSON, J. H. G. 2004. Circuitos Turísticos de Minas Gerais - Modelo de Regionalização - Ago/04. Disponível em: <www.revistaturismo.cidadeinternet.com.br?artigos/minasgerais.html $>$. Acesso em: 20 ago 2006.

BRASIL Ministério da Educação. 2001. Censo escolar 2000. Brasília, DF.

CIRCUITO TURÍSTICO TERRAS ALTAS DA MANTIQUEIRA. s/d. Disponível em: < http://www. turismo.mg.gov.br/component/content/544?task=view>. Acesso em 22 ago 2009.

CIRCUITO TURÍSTICO GRUTAS E MAR DE MINAS. s/d. Disponível em: <http://www. grutasemardeminas.com.br/>. Acesso em: 25 de ago 2009.

CIRCUITO TURÍSTICO LAGO DE IRAPÉ. s/d. Disponível em: <http://www. turismo.mg.gov.br/index2.php?option=com_content\&do_pdf=1\&id=426>. Acesso em: 21 ago 2009.

CIRCUITO TURÍSTICO NASCENTES DAS GERAIS. s/d. Disponível em: < http://www. nascentesmg.com.br>. Acesso em: 21 de ago. 2009.

CRAVO, P. M.. 2004. A criação de circuitos turísticos. Vilamoura, 2004. Disponível em: $<$ http://www.estig.ipbeja.pt/ pmmsc/papers/vilamoura.pdf>. Acesso em: 10 ago 2009.

DREHER, M.T.; SALINI, T. S.. 2008. Regionalização e Políticas Públicas no Turismo: Proposta Bem (In)tencionada Distante da Práxis!. In: V Seminário de Pesquisa em Turismo do MERCOSUL SeminTUR. Universidade de Caxias do Sul - UCS, Caxias do Sul.

DOMINGOS, M. C.; RIBEIRO, T. F.. 2008. Uma Análise do Modelo de Gestão Regional do Turismo do Estado de Minas Gerais: O Caso do Circuito Grutas e Mar de Minas. In: V Seminário de Pesquisa em Turismo do MERCOSUL - SeminTUR. Universidade de Caxias do Sul, Caxias do Sul.

EMMENDOERFER, L. 2008. A Política Pública de Regionalização do Turismo em Minas Gerais: os circuitos turísticos. Turismo em Análise, v.19, n.2, agosto.

FIPE. Fundação Instituto de Pesquisas Econômicas. 2006. Caracterização e Dimensionamento do Turismo Doméstico no Brasil. São Paulo: FIPE/USP/EMBRATUR (2002/2006). 
GOMES, B. M. A.; SILVA, V. J.; NETO, E. Q.2006. A ação coletiva em regiões turísticas: um estudo dos circuitos turísticos de Minas Gerais. Turismo - Visão e ação, v.8, n.2, p.332-330 maio/agosto.

; _ _ _ SANTOS, A. C. 2008. Políticas Públicas de Turismo: uma Análise dos Circuitos Turísticos de Minas Gerais sob s Concepção de Cluster. Turismo em Análise, v.19, n.2, agosto.

IBGE. Instituto Brasileiro de Geografia e Estatística. 2001. Censo demográfico 2000: caracterização da população e dos domicílios: resultado do universo. Rio de Janeiro.

IBGE. Fundação Instituto Brasileiro de Geografia e Estatística. 2005. Resolução do Presidente. Altera a caracterização do Sistema Geodésico Brasileiro. Rio de Janeiro.

MINAS GERAIS. 2003. Decreto n. 43.321 de 08 de maio de 2003. Dispõe sobre o reconhecimento dos Circuitos Turísticos e dá outras providências. Disponível em: < http://www.revistaturismo.com.br/ artigos/minasgerais2.html>. Acesso em: 15 mai 2007.

. Secretaria de Turismo do Estado de Minas Gerais. Informações administrativas. Disponível em: < http://www.turismo.mg.gov.br/circuitos-turísticos/informações-administrativas $>$. Acesso em: 09 set 2009.

OLIVEIRA, J. M. S. R. 2007. Potencial competitivo de circuito turístico: uma análise da rota dos tropeiros no centro-oeste de Minas Gerais. 2007. Tese (Doutorado em Administração). Departamento de Administração, Universidade Federal de Lavras.

OLIVEIRA, J. M. S. R.; SANTOS, A. C. 2006. O turismo como alternativa para o desenvolvimento da competitividade: uma análise da "rota dos tropeiros" no Oeste de Minas Gerais. FACEF Pesquisa, V.9, N.3, p.332-342.

OLIVEIRA, S. T.; JANUÁRIO, M. V. C. 2007. O turismo em São João Del Rei - Minas Gerais: Uma análise preliminar. CULTUR - Revista de Cultura e Turismo, Ano 01, N.1, Edição Especial, Out, p.110 .

PNUD. 2003. Atlas do Desenvolvimento Humano no Brasil 2003. Brasília: PNUD/IPEA, Fundação João Pinheiro.

PREFEITURA MUNICIPAL DA CIDADE DE FORMIGA. Disponível em: < http://www.formiga. mg.gov.br/>. Acesso em: 12 ago 2009.

PREFEITURA MUNICIPAL DA CIDADE DE GRÃO MOGOL. Disponível em: <http://www. graomogol.mg.gov.br/portal1/municipio/noticia.asp?iIdMun=100131317\&iIdNoticia=28500>. Acesso em: 11 ago 2009.

PREFEITURA MUNICIPAL DA CIDADE DE ITAMONTE. Disponível em: $<$ http://www.itamonte. mg.gov.br/>. Acesso em: 13 ago 2009.

PREFEITURA MUNICIPAL DA CIDADE DE MATO VERDE. Disponível em: <http://www. matoverde.mg.gov.br/portal1/municipio/hospedagem.asp?iIdMun=100131476>. Acesso em: 12 ago 2009.

PREFEITURA MUNICIPAL DA CIDADE DE PASSOS. Disponível em: <http://www.passos. mg.gov.br/>. Acesso em: 12-15 ago 2009. 
SANTOS, A. A. 2004. A importância do circuito turístico para o fomento da economia e da preservação ambiental - Caso "São Roque de Minas". Dissertação (Mestrado em Administração). Universidade Federal de Lavras.

TEIXEIRA, A.; VICENTIM, F. M.; AGUIAR, V.2006. Circuitos turísticos e sua importância para o turismo no espaço rural brasileiro. In: VII Congresso Latino Americano de Sociologia Rural. Equador. Anais...Quito.

Recebido em: 29/10/2009

Aprovado em: 17/01/2010 